\title{
A ambiência compondo a moradia adequada para idosos de baixa renda
}

\author{
The ambience composing adequate housing for low income elderlys
}

\author{
Luzia Cristina Antoniossi Monteiro* \\ Vania Aparecida Gurian Varoto** \\ Nayara Mendes Silva*** \\ Aldora Eugênia Freire ${ }^{* * * *}$
}

\section{Resumo:}

O Brasil enfrenta desafios com o aumento no número de idosos. Frente a esta situação, aumentam as demandas pelo direito à cidade, impactando a gestão pública e a sociedade. $O$ envelhecimento populacional e o desenvolvimento urbano são processos distintos, heterogêneos e igualmente complexos. Atrelado ao direito à cidade, sobressai a questão da moradia, que, embora a Constituição Federal estabeleça como um direito fundamental, o idoso de baixa renda tem dificuldade para alcançá-la. Morar de forma digna perpassa condições objetivas e alcança aspectos subjetivos, preponderantes na preservação da identidade, no sentido de pertencimento ao lugar, significado da ambiência. Esse artigo analisa a ambiência na formação da moradia digna em um condomínio exclusivo para idosos de baixa renda. Com a longevidade eleva-se a demanda por moradia, pois aumenta número de idosos morando sozinhos - desafio para as políticas públicas que necessitam repensar lugares que promovam a participação na sociedade e a qualidade de vida no cenário urbano.

Palavras-Chave: Moradia Digna. Ambiência. Políticas Públicas. Envelhecimento. Saúde.

\begin{abstract}
:
Brazil faces challenges with the increasing proportion of elderly in the total population of the country. Although the Federal Constitution establishes housing as a fundamental right, low-income seniors have difficulty to achieve it. Living in dignity pervades objective conditions and reaches subjective aspects, preponderant in the preservation of identity and of belonging the place, that is the meaning of ambience. This article analyzes the ambience in the formation of adequate housing in an exclusive condominium for low-income seniors. With longevity rises the demand for housing, because it increases the number of elderly living on their own - challenge for public policies that need to rethink places that promote participation in the community and quality of life.
\end{abstract}

Keywords: Dignified Housing. Ambience. Public Policies. Aging. Health.

\footnotetext{
* Advogada. Doutora em Engenharia Urbana pelo Programa de Pós-Graduação em Engenharia Urbana - UFSCar. Docente do Departamento de Gerontologia e da Pós-Graduação em Gerontologia - UFSCar. E-mail: cristinaantoniossi4@gmail.com

** Terapeuta Ocupacional. Especialista em saúde coletiva e Doutora em Engenharia de Produção - UFSCar . Docente do Programa de Pós-Graduação em Gerontologia-PPGGero - UFSCar. E-mail: vania_varoto@yahoo.com.br

*** Bacharel em Gerontologia e Mestranda do Programa de Pós-Graduação em Gerontologia pela Universidade Federal de São Carlos (UFSCar). E-mail: nayara.mm@live.com

**** Bacharel em Gerontologia pela Universidade Federal de São Carlos (UFSCar). E-mail: aldoraeugenia@yahoo.com.br
} 


\section{Introdução}

O Brasil e o mundo enfrentam desafios e demandas com o processo de envelhecimento. As estimativas mundiais, afirmam que o número de pessoas com mais de 60 anos irá triplicar em 50 anos, passando de 606 milhões no ano 2000, para quase 2 bilhões em 2050 (UNITED NATIONS, 2003). No Brasil, segundo Instituto Brasileiro de Geografia e Estatística - IBGE, o número de pessoas idosas ultrapassa 26 milhões (IBGE, 2013).

De acordo com Prado e Perracini (2011), pesquisas recentes revelam a diminuição do número de idosos morando com filhos nos Estados Unidos e na Europa. No Brasil essa tendência triplicou em 20 anos, entre os anos 1992 e 2012 passou de aproximadamente 1 milhão para quase 4 milhões de idosos residindo sozinhos (IBGE,2013). Isso representa o exercício da autonomia e da independência, sinônimo da velhice bem-sucedida. No entanto, a concretização desse desejo é mais fácil para idosos com melhores níveis de escolaridade e renda.

Atrelado ao envelhecimento populacional, tem-se cada vez mais nítida a necessidade de se alcançar o direito à cidade. Segundo Thibaud (2010) "a cidade contemporânea está passando por várias mudanças que estão redesenhando sua aparência e fazendo emergir novos contextos de sensibilidade". Para o autor, as mudanças no modo de vida urbana demandam novas maneiras de abordagens para seu entendimento, indicando o recente crescimento do interesse em ambiente sensorial dos espaços habitados, focados na percepção, na paisagem, nas sensações, no corpo e nas ambiências.

O envelhecimento populacional e o desenvolvimento urbano são processos distintos, heterogêneos e igualmente complexos. Desta forma, em relação ao direito à moradia digna para a pessoa acima de 60 anos, o ideal seria considerar a preferência, a percepção e a necessidade do morador, transmitindo a sensação de agradabilidade e de pertencimento ao lugar.

Para Malard (2004, p.3) "o conjunto de qualidades que fazem de um lugar um domínio sagrado, constitui a ambiência desse domínio". É, portanto, a troca contínua e recíproca entre o usuário e o espaço, ajustando-se às necessidades e desejos humanos desenvolvidos no processo de adequação, tornando-os próprios para o uso.

A abrangência do conceito de ambiência não se limita aos aspectos urbanísticos ou físicos, estruturais. Também alcança as relações de afinidade e de interações desenvolvidas 
com o entorno da moradia, que pode representar novos vínculos de amizade na velhice, e relacionam-se com o conceito de apoderar-se do espaço urbano, tê-lo próprio ao seu uso. Representa a habitabilidade, onde a moradia é vista como meio de acesso a saúde e crescimento individual em todos os seus aspectos e a integração socioespacial do idoso no contexto urbano (ELALI, 2009; PERRACINI, 2011; GABRILLI, 2013).

Embora a realidade urbana brasileira seja diferente disso, a moradia digna deveria atender aos desejos pessoais de onde e como se deseja morar. Então, o morar seria uma questão de foro íntimo para o idoso, conforme estabelecido pelos Direitos Humanos, firmados por Pactos Internacionais, Leis e Estatutos de cada país. Para tanto, dispondo do essencial à dignidade humana, pois o meio ambiente físico ou social pode refletir uma experiência positiva ou negativa sobre o envelhecimento, sendo um facilitador ou uma barreira para desempenho das atividades de vida diária.

Para a camada de baixa renda, concretizar o sonho da moradia adequada fica na dependência da implementação de políticas públicas. Nesse sentido, para atender a heterogeneidade desse público, há necessidade de efetivar de diversas modalidades habitacionais, pois de acordo com as regiões, a cultura, a etnia e a história de vida, mudam as preferências.

Uma modalidade habitacional que os municípios do estado de São Paulo têm implementado são núcleos, ou conjuntos habitacionais para idosos, ou ainda "condomínios exclusivos para idosos", termo utilizado para identificar as casas ou apartamentos circunscritos em área delimitada por muros, cercas, ou alambrados, construídos por meio de política pública habitacional para idosos de baixa renda, independentes para realizar as atividades da vida diária, e que sejam sozinhos ou com laços familiares enfraquecidos.

Nesse cenário, este artigo analisou aspectos da ambiência manifestados espontaneamente em entrevistas realizadas com moradores de um condomínio exclusivo para idoso de baixa renda localizado no interior do estado de São Paulo. Tratou-se de um recorte de pesquisa maior que foi desenvolvida ao longo de dois anos com auxilio regular da Fundação de Amparo à Pesquisa do Estado de São Paulo (FAPESP), cujo objetivo foi analisar a acessibilidade intramuros e no entorno do residencial, bem como a funcionalidade dos moradores. Nesse artigo destacaram-se pontos de vista emanados pelos moradores sobre a ambiência, possibilitando aos pesquisadores inferir aspectos subjetivos e objetivos que permeiam o lugar de moradia. 
Os resultados apontaram a relevância desse espaço, já que todos os entrevistados aprovaram essa política pública municipal, localizada intramuros. Os entrevistados também elencaram pontos relevantes, que, na visão de uns é positivo, e no olhar de outros é negativo, como a segurança e a acessibilidade, desse modo corroborando o pensamento de que a ambiência é intrínseca à percepção de cada pessoa, com significados e representações diferentes que a influenciam, ainda que se trate da convivência em uma mesma comunidade de moradores de faixa etária semelhante.

\section{O Direito à Moradia Digna e a Ambiência}

A moradia é direito social estampado no artigo 60 da Constituição Federal, reconhecido internacionalmente pela Declaração Universal dos Direitos Humanos (1948) e ratificada no Pacto Internacional dos Direitos Sociais, Econômicos e Culturais (1966) que reconhece o dever do Estado de prover, por meio de políticas públicas a concessão deste direito a população de baixa (BRASIL, 1992).

A Secretaria de Direitos Humanos da Presidência da República do Brasil ao tratar das particularidades qualitativas da moradia digna, o faz com base nas necessidades físicas, enfatizando também, o preenchimento de valores subjetivos individuais intrínsecos à espécie humana.

Tem-se ainda, ressaltadas as necessidades intelectuais humanas com referência ao domínio da inteligência, da espiritualidade, do gosto, estilo de vida e costumes relacionados à cultura de cada pessoa. Assegurando o preenchimento de qualidades subjetivas necessárias à vida humana, por exemplo a preservação da intimidade, o direito de privacidade e expressão do afeto. Demonstrando a preservação do respeito aos valores morais e culturais de cada pessoa (BRASIL, 2013). Assim, é a sensação de pertencimento o fator que torna um lugar um lar. Essa sensação é definida por Thibaud (2010) como sendo onde "a ambiência se apoia, se constitui e repousa".

A Organização das Nações Unidas refere-se à moradia digna no "Comentário Geral 4, do Comitê dos Direitos Econômicos, Sociais e Culturais das Nações Unidas para o Controle dos Tratados em Matéria de Direitos Humanos", também na Comissão sobre Assentamentos Humanos, conceituando a moradia digna e adequada, caracterizando atributos objetivos e subjetivos que contribuem para sua qualificação. 
Nesta perspectiva a moradia é vista "como componente do direito a um padrão de vida adequado" (ONU, 2000, apud Brasil, 2013 p. 10). Especifica também, prioridade de acesso aos grupos sociais discriminados e estigmatizados: "idosos, crianças, deficientes físicos, doentes terminais, pessoas com HIV, doenças crônicas e mentais". Garantido ainda às vítimas de desastres naturais e moradores de áreas propensas a desastres, pois "a discriminação e a segregação da habitação promove a pobreza e marginalização econômica".

Neste cenário, a localização da moradia digna e adequada torna-se fator determinante de acesso ao trabalho, serviço de saúde, escola, creche e outros benefícios importantes para o desenvolvimento social. Contemplando também a subjetividade dos seus moradores, para possibilitar a expressão e preservação da identidade, a diversidade racial e cultural (OHCHR; ONU-HABITAT, 2009 apud BRASIL, 2013, p.20).

No Brasil, recentemente a criação da Lei Brasileira de Inclusão da Pessoa com Deficiência (Estatuto Da Pessoa Com Deficiência) estabelece:

a moradia para a vida independente da pessoa com deficiência, prevendo a adequação estrutural, serviços de apoio coletivos e individualizados que ampliem o grau de autonomia de jovens e adultos com deficiência (Lei no 13.146/15, artigo 3으, inciso $\mathrm{XI}$ ).

Em relação ao direito à moradia para a pessoa idosa, no Brasil, o artigo 37 do Estatuto do Idoso define que: "o idoso tem direito à moradia digna, no seio da família natural ou substituta, desacompanhados de seus familiares, quando assim o desejar, ou ainda, em instituição pública ou privada" estabelecendo assim, a autonomia do idoso com relação a formas de amparo e moradia na velhice.

Já em seu artigo 38, enfatiza a prioridade ao idoso nos programas habitacionais, públicos ou subsidiados com recursos públicos para aquisição de casa própria. Indicando reserva mínima de 3\% de unidades residenciais, em programas habitacionais populares em concordância com demandas regionais.

Ao lado da legislação, os princípios do Desenho Universal fortalecem os aspectos que integram a moradia digna, por meio de normas e diretrizes para adequação de habitações com parâmetros que levam à criação de moradias que atendam as expectativas e necessidades de todos os públicos, sem necessidade de adaptação, incluindo os recursos da tecnologia assistiva. O Desenho Universal foi idealizado nos anos 1990 nos Estados 
Unidos por um grupo de pesquisadores, com a proposta de universalizar o padrão arquitetônico das edificações, tornando os ambientes construídos capazes de atender o ser humano em sua diversidade. Para tanto estabelece sete princípios, que constituem critérios e parâmetros para as edificações a serem seguidos universalmente.

$\mathrm{O}$ acolhimento de tais critérios garante o direito de acesso para além das medidas e estruturas das edificações, abre caminho para a oportunidade de desfrutar novas dimensões da vida diária, atividades, serviços, programas, institucionais e políticas governamentais e institucionais.

Desse modo o Desenho Universal com critérios técnicos também contribui para a melhora da qualidade de vida e prestigia sensações como segurança e inclusão, perpetrando o sentido de bem-estar subjetivo da "casa própria" definida por Tuan (1983) como o "lar", afirmando que os seres humanos estão sempre à sua procura, como um abrigo, refúgio de aconchego, luz e felicidade.

Tuan (1983) afirma que todos os homens apresentam um desejo comum: "ter seu lugar no mundo" em referência ao lugar de aparência agradável, seguro para onde sempre se quer retornar. $\mathrm{O}$ autor refere-se um lugar cujo tempo e a distância acresce de valor afetivo: a "velha casa", a pátria, um lugar da infância. Estabelecendo o valor do lugar como suporte primordial para desenvolvimento da vida. Nesse sentido, imprescindível considerar as condições das ambiências.

\section{A Ambiência}

Em dicionários de língua portuguesa, o significado da palavra ambiência abrange "o meio (habitat) em que vive um vegetal ou animal"; ou seja: o que rodeia; meio físico ou moral, alegria e entusiasmo (PRIBERAM, 2016; MICHAELIS, 2017). Ainda, espaço arquitetonicamente organizado e animado, meio físico, estético e psicológico, especialmente preparado para o exercício das atividades humanas, conjunto das características sociais, culturais, emocionais que rodeiam uma pessoa e que influenciam seu comportamento.

É possível afirmar que o significado da palavra ambiência percorre trajetos amplos e abrangentes, como "atmosfera" e "espaço aberto", caminhando para algo intrínseco ao 
ser humano referindo-se a "aura" enquanto essência da individualidade e "caráter" e representação de valores morais.

$\mathrm{Na}$ arquitetura, o termo ambiência é utilizado como adjetivo em referência à estética dos ambientes construídos. Segundo Malard (2001) a escassez de estudos sobre o tema, faz com que, a palavra ambiência quando mencionada por arquitetos "tende a parecer uma dimensão sobrenatural e desconhecida do espaço".

As indagações repousam sobre a possibilidade de conceituar algo estético, o belo. O que é a beleza? Como definir algo que tem sua representatividade pautada nas sensações e valores individuais? Ambiência e estética são conceitos subjetivos, definidos por parâmetros referentes a valores morais, culturais e sociais, ainda ligados à etnia e época de cada um.

Para Maffesoli (2006, p. 274) "há na ideia de estética uma "paixão de viver" que tende a chocar os espíritos mais estabelecidos que não são capazes, de fato, de compreender e analisar os pensamentos e modos de vida cotidianos". Com intensidade a autora emprega a expressão "paixão de viver" aguçando a percepção sobre a beleza e as sensações construídas na vivência cotidiana, onde ambiência constitui-se de preferências individuais, de estilos de vidas, costumes locais, culturais e valores morais entre outros. É a impressão, sensação, marca ou sinal que fica de algo exterior.

Enquanto qualidade arquitetônica, a ambiência para Marlard (2004) "é composta por um sistema de objetos funcionais, subdivididos em dois grupos. O primeiro grupo refere-se à estrutura dos arranjos, definida como disposição e combinação de objetos em um ambiente, como por exemplo, a maneira de dispor as casas em um residencial, que seguem predefinições para garantir sua funcionalidade. Já o segundo grupo, referente à estrutura da ambiência, está relacionada às cores, texturas e outros materiais e objetos, utilizados em suporte a estrutura dos arranjos. Estes são capazes de comunicar características sociais, relações de hierarquia, religião, valores morais, culturais e econômico de cada época e da região de origem (MALARD, 2004).

Todavia, Rheingantz (2001, p.12) ressalta que "o ambiente não se restringe às relações medidas e seus meios materiais" perpassa aspectos físicos, abrange as relações de convívio, de afinidade, situa-se na qualidade dos afetos e das relações sociais desenvolvidas, definem a qualidade da ambiência deste lugar. 


\section{Avanço no conceito de ambiência no contexto urbano}

A geografia humanista intenta explicar a relação do "lugar" que deve ser entendida no sentido amplo e subjetivo, pois seu valor está nas sensações que ele desperta (TUAN, 1983, Apud MELLO, 2011). O autor destaca a concepção de lugar, "pode ser um lugar natural, uma bela paisagem, ou ainda lugares construídos como "uma velha casa, um bairro, a cidade e a pátria" contextualizando a fundamentalidade dos sentidos humanos visão, olfato, paladar e tato para a percepção do lugar (TUAN 1983 apud MELLO, 2011, P.09).

Deste modo, cheiros, sabores, texturas e cores, formam impressões na memória, especialmente na memória afetiva, sendo associados a sentimentos, posteriormente constituem gatilhos que levam a lugares do convívio durante a vida. Assim, um aroma pode despertar a lembrança de um lugar da infância, por exemplo, a casa dos avós, e ainda, uma brisa pode resgatar memórias, de um lugar, um passeio, uma viagem ou um dia especial de verão. Momentos agradáveis que remetem acolhimento e aconchego. Todavia, os mesmos elementos podem remeter a lembranças tristes de lugares que não desejamos voltar.

Tuan (1983) afirma que é impossível entender os espaços dos homens sem a concepção de sua geografia humanista. Segundo o autor e existência humana é marcada pela sua relação com o espaço, lugar, tempo e o movimento.

A existência humana é marcada pela busca constante, não obstante por uma posição geográfica, pode ser uma posição social, um cargo, o reconhecimento, ou ainda uma situação tranquila financeira e emocional. Inspirações que impulsionam rumo ao futuro, ao crescimento intelectual estabelecido na apropriação do espaço e lugar. Tuan (1983) afirma que o lugar é "pleno de continuidade e descontinuidade", assim, suscita a reflexão sobre ser alvo simultâneo de busca e interrupções, preferências, necessidades econômicas e sociais, estabelecendo a relação entre espaço, lugar, tempo e movimento.

Para Thibaud (2010, p. 31) "as cidades contemporâneas passam por transformações que se refletem no cotidiano das pessoas e nos sentimentos que se desenvolvem no contexto urbano" neste sentido salienta que: "ar, som, luz, cheiro e outros recursos que possibilitam a percepção da ambiência no contexto urbano são forjadas artificialmente, portanto perpassam as edificações e estão até nas coisas mais obvias e invisíveis (THIBAUD, 2010, p. 31). 
O ritmo da sociedade moderna, o dinamismo tecnológico da atualidade, mudanças ambientais, motivadas por necessidades sociais e econômicas influenciam para constante reconstrução do território urbano.

Em referência aos "fenômenos de natureza ecológica" - as rápidas mudanças climáticas, e de "natureza artificial" - a aclimatizar dos ambientes construídos, as festividades, os eventos e acontecimentos urbanos, sobrepostos simultaneamente com o barulho dos automóveis, propagandas estampadas em painéis gigantes, pichações, objetos abandonados nas ruas, comércio em calçadas, obras infindas. O som das máquinas executando obras, espaços verdes cada vez mais escassos ou construídos artificialmente e presença humana compõem o espaço urbano em eterna transformação.

A ambiência urbana é composta por mudanças e acontecimentos nem sempre visíveis, mas perceptíveis, que afetam de diferentes formas, diferentes pessoas. Assim, não basta sentir a ambiência dos centros urbanos, é preciso atentar para sua procedência: onde se apoia, sobretudo, o que produz e transforma na vida cotidiana. Nas atmosferas funcionais e privadas, como exemplos, os condomínios- representam oásis de segurança e conforto em relação ao resto da cidade; os shoppings centers- onde luz, iluminação, som e temperatura são criados para interferir, até mesmo a percepção temporal.

Thibaud (2010) propõe cinco operações para perceber a ambiência dos centros urbanos. Para cada operação o autor elege uma palavra-chave e ascende à reflexão sobre novas perspectivas de perceber a influência da ambiência nos espaços e na vida cotidiana. Primeira operação, palavra-chave: médium, se diz de alguém que acredita ser capaz de permear entre coisas palpáveis e as espirituais, ou seja, situar-se entre concreto e abstrato conceber a essência humana.

Mais que as evidencias da presença de fatores visíveis e invisíveis nos ambientes, é possível constar o que esses fatores promovem, segundo Thibaud (2010, p. 32) "o design urbano não se debruça mais tão somente sobre os objetos, mas sobre o que há entre os objetos". Dessa forma é possível afirmar que a ambiência é o que se vê, que se sente, é o que surge na união de todos os elementos que compõe e envolve o espaço, sobretudo é o que desperta, é a essência do lugar.

Segunda operação, palavra-chave: ressonância, propriedade do som que faz um objeto vibrar em determinada frequência. Thibaud (2010) revela que a operação constitui em "compor com tons afetivos, reconhecer a diferença entre um meio ambiente e uma 
ambiência". Assim, entende-se que elementos do ambiente têm o "poder" de fazer vibrar, estremecer através do maior ou menor afeto que a ambiência desperta.

Terceira operação, palavra-chave: coalescência, dar coesão às situações urbanas, unir todos os pontos que constituem uma ambiência: em qualquer situação existe um conjunto heterogêneo de elementos participantes ativos. Para Thibaud (2010, p.33) "uma ambiência não se reduz a uma forma de luz ou a uma maneira de andar, a um material de construção ou há um tempo chuvoso", mas é preciso religar os vários elementos entre si, e perceber o produto desta união, mantendo unidos.

Quarta, palavra-chave: manutenção, preservar a memória de eventos corriqueiros que ocorrem, considerando que nem sempre os elementos que estão em destaque é o que dá consistência e compõe a ambiência. Segundo Thibaud (2010, p.34) a operação consiste em "multiplicar as cenas microscópicas do cotidiano" trata-se da ambiência constituída da influência cultural nos eventos que ocorrem diariamente nas metrópoles.

Quinta operação, palavra-chave: impregnação, deixar embeber-se das coisas muito sutis dos ambientes, onde habitar constitui em moldar e ser moldado ao contexto habitado, tornar-se parte constituinte da ambiência. Às vezes torna-se necessário sair do lugar e então retornar para ter consciência daquilo que já estava lá. Neste sentido, afirmase que "a ambiência valoriza, sobretudo a porosidade que existe entre os habitantes e seu meio de vida, a capacidade de sentir e incorporar as pequenas modulações de um espaço sensível". Cabe então perceber as diversas nuances onde a ambiência destoa, cabe também examinar valores éticos dos seus diversos usos, seu significado e as suas consequências. Muitas vezes utilizada como recurso principal para fins econômicos, estratégia de varejo, tipos de negócios, outras vezes atendendo necessidades ambientais contemporâneas.

\section{Ambiência e a interação com a saúde e habitação}

A Organização Mundial da Saúde - OMS ao estimular que os Estados-parte apliquem os Princípios de Saúde na Habitação, ressalta que as condições de habitação e de vida quando deficientes são associadas às mais altas taxas de mortalidade e morbidade (WHO, 2000). Estudos epidemiológicos investigam características atinentes à vizinhança e o entorno das moradias, que refletem na saúde individual e coletiva dos moradores (SANTOS et. al. 2007). 
Por outro lado, boas condições ambientais, como iluminação, calçadas limpas, rampas acessíveis, serviços de transporte público entre outros fatores, facilitam o deslocamento de pessoas com necessidades especiais, aumentam o nível de atividade física, de participação social em comunidade, proporcionando a agradabilidade e refletindo positivamente sobre a saúde individual e dos grupos (OMS, 2008).

Na perspectiva de viabilizar aspectos favoráveis à promoção e humanização dos serviços de saúde, a ambiência é vista como um facilitador das ações e das relações entre funcionários e usuários do Sistema Único de Saúde brasileiro, conforme a Política Nacional de Humanização da Saúde (PNH/SUS,2003). Nessa política, o Sistema Único de Saúde - SUS apresenta uma série de medidas visando valorizar relações e vínculos por meio da ambiência, "tratamento dado aos espaços físicos, entendido como espaço social, profissional e de relações interpessoais" no território da saúde populacional (BRASIL, 2010).

Desta forma no âmbito da saúde pública, a ambiência é reconhecida como elixir capaz de facilitar a comunicação entre gestores, trabalhadores e usuários dos serviços do SUS, um utensílio capaz de combater "atitudes e práticas desumanas" no âmbito da promoção de saúde (BRASIL, 2010).

No âmbito da saúde mental, a ambiência também está inserida na Política de Humanização da Saúde do Ministério da Saúde. Os Centros de Atenção Psicossocial - CAPS incorporaram princípios da ambiência como ferramenta orientadora de novas tecnologias, na promoção e na reabilitação psicossocial. Também como elemento para a integração do usuário com o espaço de saúde. Nesta perspectiva, a ambiência é vista como nova tecnologia que apresenta o potencial de acolher a subjetividade dos usuários e atuar para valorização de práticas e conhecimentos contidos nas equipes multidisciplinares.

A ambiência e a habitabilidade são protagonistas da inserção e inclusão socioespacial do idoso no território, sendo conceitos referentes às condições do ambiente como determinante da promoção de saúde. A literatura registra pesquisas que identificam os efeitos de fatores do ambiente de moradia e seu entorno sobre a saúde individual e coletiva.

Neste sentido Santos et al (2007) apresentam revisão literária de estudos que avaliam a influência do contexto de moradia - vizinhança sobre o indicador autoavaliação de saúde em diversos países do mundo. O indicar autoavaliação de saúde é importante preditor de mortalidade, possibilitando mensurar aspectos subjetivos relacionados à saúde 
individual, principalmente entre pessoas idosas. Apontando a percepção íntegra do indivíduo sobre si mesmo, tornando possível mensurar as dimensões que compõem a saúde biológica, a psicológica e a social. Abrangendo fatores ambientais, econômicos e particulares, como, desemprego, renda, habitação e hábitos de vida. Höfelmann (2012) afirma que os atributos do local nos quais as pessoas vivem, bem como suas percepções sobre estes, são importantes determinantes de saúde.

A habitabilidade trata-se de amplo conjunto de fatores que compõem a moradia, sistemicamente favoráveis ao direito à cidade. Onde o acesso à infraestrutura e equipamentos públicos possibilita o "pleno exercício de fruir, usufruir e construir um espaço com qualidade de saudável/habitável" (COHEN, et al., 2007, p. 194).

Já a habilidade da habitação segundo a Associação Brasileira de Normas Técnicas ABNT (NBR 10.152/87) é conceituada pelas qualidades que definem seu desempenho, componentes estruturais referentes a sua funcionalidade, conforto tátil e antropodinâmico, durabilidade, manutenibilidade e segurança física de seus habitantes. Também pelo desempenho térmico, acústico, lumínico, higiene, estanqueidade. E ainda fatores ambientais como a qualidade do ar, impacto ambiental e sustentabilidade (CHVATAL, 2014).

Cohen et al (2007) afirmam que a ambiência na habitação perpassa a adequação cultural, pela utilização dos materiais, dos móveis, dos pisos, das paredes, favorecendo fatores ambientais temperatura, ventilação, luminosidade, atendendo a necessidades físicas, psicológicas e socioculturais. Nesse sentido é inclusiva para a moradia digna, se estende a uma rede de inter-relações de afinidades favoráveis para a manutenção da vida, já que esta exerce influências na qualidade de vida do indivíduo.

\section{A Ambiência em um Condomínio Exclusivo para Pessoas Idosas de Baixa Renda}

A situação ideal em relação à moradia para pessoa idosa seria aquela que contemplasse condições objetivas e subjetivas tendentes a preservar a autonomia e a estimular o sentido de pertencimento ao lugar. Nesse sentido, programas habitacionais populares, por exemplo, o "Minha Casa Minha Vida", do governo federal, embora forneça o espaço físico, deixa a desejar no que tange a condições impares que deem conta das 
condições subjetivas que transforme aquele local em verdadeiro lugar de moradia, contemplando a habitabilidade.

Aspectos que influenciam diretamente o cotidiano dos cidadãos e contribuem para a qualidade de vida devem ser pensados no planejamento urbano, como características ambientais, identidade dos bairros e o caráter das cidades (MARTINS, et al, 2013). Essas condições aproximam a pessoa do lugar que habita, tornando a casa um verdadeiro lar e despertando o melhor sentimento no morador, contribuindo, inclusive, para a sua qualidade de vida.

Despontam no Brasil políticas habitacionais com vistas à moradia como componente da atenção integral à pessoa idosa, que pretendem garantir condições de acesso e participação social. Um exemplo é o condomínio exclusivo para pessoas idosas analisado por essa pesquisa. Foi implementado por meio de política pública municipal, no ano de 2010, para pessoas idosas que atendam aos seguintes critérios: renda de zero a um salário mínimo, independência para realizar atividades cotidianas e de autocuidado, vínculos familiares enfraquecidos, residir sozinho ou com cônjuge.

Trata-se de um condomínio horizontal com 33 casas, construídas ao redor de um centro de convivência, estabelecido ao lado de via férrea, operada pela Ferrovia Paulista (FEPASA) e cercado por alambrados, formando uma comunidade intramuros. Esse lugar de moradia não segue os padrões preconizados pelo desenho universal, sendo apenas 2 unidades adaptadas para pessoas com algum tipo de necessidade. Como parte da pesquisa teceu-se a caracterização sociodemográfica dos moradores no ano de 2016. Dos 34 moradores, foram entrevistados 25 idosos que estavam na faixa etária entre 64 e 89 anos de idade, sendo que a média de idade foi de 74,64 anos (DP: 6,601), e em sua maioria eram mulheres (72\%). Dos participantes, 32\% (n:08) são solteiros, $24 \%$ (n:06) são viúvos, 24\% (n:06) são divorciados e outros $20 \%$ (n: 05) são casados.

Com relação ao nível educacional, apurou-se o baixo nível de escolaridade dos moradores, tendo em vista a média de 3,76 anos de estudo (DP: 3,32). Sendo que, $80 \%$ ( $n$ : 20) tem Ensino Fundamental Incompleto, outros $12 \%$ ( $n: 03$ ) analfabetos que declararam nunca terem frequentado a escola, 4\% ( $n: 01)$ com Ensino Fundamental Completo e apenas 4\% (n: 01) tem Ensino Superior Completo.

Assim como o nível de escolaridade, a renda dessas pessoas é baixa, e se concentra na faixa de 1 salário mínimo, pois $80 \%$ deles $(n: 20)$ recebe esse valor, seguidos 
por $12 \%$ (n: 03) que recebem mais de 1 salário mínimo e $8 \%$ (n: 02) que relataram receber menos de 1 salário mínimo. Vale ressaltar que para ingresso enquanto morador neste condomínio deve ter renda mensal até um salário mínimo.

De acordo com as entrevistas as profissões dos 25 participantes eram relacionadas ao desempenho de funções menos especializadas ou que exigem menor grau de formação. Assim, 36\% ( $n$ : 09) das mulheres desempenhavam função de doméstica, enquanto os outros se dividiam entre carpinteiro, soldador, eletricista, comerciante, trabalhador rural, industriário, metalúrgico, pedreiro, cozinheira, caminhoneiro, e outros trabalhadores braçais e de serviços gerais. Apenas uma entrevistada, que possuía ensino superior completo desempenhava as funções de pedagoga.

Dentre os entrevistados, $28 \%$ (n: 07) são naturais da própria cidade em questão, enquanto outros $56 \%$ (n: 14) nasceram em outras cidades do Estado de São Paulo e 12\% (n: 03) são naturais de cidades da região Nordeste do país.

A maioria desses idosos (72\%) reside sozinha atualmente, sendo que outros $24 \%$ residem com o cônjuge e 4\% (apenas 01 idosa) mora com o filho. No entanto, antes de se mudarem para o conjunto habitacional quase todos (84\%) já residiam nesse município, sendo que $40 \%$ deles moravam com familiar(es).

Levando-se em conta que o condomínio foi inaugurado no ano de 2010, o tempo médio de residência dos entrevistados foi de 36,52 meses, porém houve uma grande variabilidade nesse tempo entre os moradores, confirmado pelos indicadores estatísticos (DP: 22,796). O maior tempo de residência entre os entrevistados foi de 05 anos, que é o tempo de moradia de 08 indivíduos (32\%), seguido por seis indivíduos que moram há 04 anos (24\%), enquanto cinco pessoas residiam há menos de 01 ano (20\%).

A grande diversidade no perfil sociodemográfico dos moradores mostra a heterogeneidade deste segmento etário, fator que influencia diretamente a percepção, diferenciando as opiniões sobre mesmo aspecto, no mesmo lugar de moradia. Para Camarano e Pasinato (2004):

\footnotetext{
Parte-se da hipótese de que esse grupo experimentou trajetórias de vida diferenciadas que vão afetar as suas condições de vida na última etapa. Essas trajetórias são fortemente marcadas pelas desigualdades sociais, regionais e raciais em curso no país. As políticas sociais podem reforçar essas desigualdades ou atenuá-las, bem como os mitos, os estereótipos e os preconceitos em relação à população idosa (CAMARANO; PASINATO, 2004).
} 
Além de caracterizar o perfil, a entrevista objetivava conhecer a percepção dos moradores sobre a acessibilidade e a segurança nos espaços intramuros. Sobre a tipologia de moradia, constituída por espaço cercado por alambrados, todos, $100 \%$ dos entrevistados aprovaram o tipo de moradia cuja localização é intramuros, alegando que há "segurança" e "privacidade". Essa percepção é refletida na fala de alguns idosos que destacam a tranquilidade do lugar em que residem.

Uma das perguntas realizadas almejava verificar pontos positivos e negativos sobre morar nesse espaço. E nesse sentido chamou a atenção, pois foram apontados aspectos físicos e arquiteturais do condomínio, como também pontos que desvelam aspectos de foro íntimo, sensações de agradabilidade e aflições pessoais. Esses aspectos relatados pelos moradores caracterizam mais que simplesmente pontos positivos e negativos, eles apontam dimensões que compõem a ambiência. Essa experiência vivenciada pelos pesquisadores corrobora o pensamento que indica que a ambiência é facilmente observada nas ações cotidianas e no processo valorativo atribuído ao lugar. Quanto mais valores positivos ou negativos atribuem-se a um lugar, maior a influência da ambiência sobre a pessoa (ELALI, 2009).

Fato esse justificado pela dimensão subjetiva da ambiência. Muitas vezes pessoas que fazem parte de um grupo com características similares, como idade, gênero e padrão socioeconômico, apresentam habilidades e necessidades distintas, portanto apresentam valores igualmente diversificados em relação a elementos que despertam sensações de segurança e insegurança (SANT'ANNA; KILIMNIKI, 2011).

A ambiência é multissensorial, ou seja, resulta de processo cognitivo advindo de estímulos que acontecem pela interação do indivíduo e do ambiente, tudo que nos cerca e rodeia. Nesse sentido, o estudo constatou que um mesmo sentimento ou fato, como a questão da segurança e da acessibilidade, por exemplo, é percebido como ponto positivo para uns, e negativo para outros.

A segurança foi citada como aspecto positivo por $24 \%$ dos idosos, enquanto que em aspectos negativos, representou 4\% (apenas uma) das citações. Representando o segundo aspecto positivo mais citado pelos entrevistados, pode ser atribuída aos motivos que justificam a mudança para o condomínio, uma vez que $16 \%$ dos idosos revelaram que a sua vinda para o núcleo habitacional ocorreu devido às condições precárias da moradia anterior, bem como a falta de ter onde morar. Já enquanto ponto negativo, a segurança 
refere-se à outra questão que foge do pressuposto anterior, pois a idosa que relatou sentirse insegurança, informou que teme por assaltos, principalmente nos dias que vai ao centro receber a aposentadoria.

A afirmação de insegurança feita por uma idosa também se opõe aos relatos de alguns idosos (8\%) que relataram a tranquilidade que é viver no condomínio, por ser "calmo" e afastado do centro da cidade. Entretanto, a tranquilidade referida também se confronta com o principal aspecto negativo citado pelos moradores: a distância entre o condomínio e o comércio, representando $32 \%$ das falas. Nesse sentido, é perceptível a diferença de opiniões entre os moradores, pois ao passo que o local é caracterizado como tranquilo por ser distante do comércio, a distância também é motivo de queixa de outros moradores.

Pode-se inferir ainda, que a distância entre o condomínio e o comércio constitui em um agravante à segurança, visto que na fala dessa idosa tem-se nitidamente a sensação de insegurança atrelada à violência presente no cenário urbano, e o fato do condomínio ser longe do comércio é um fator que contribui para sua vulnerabilidade. Verifica-se, neste sentido, a contradição das respostas norteadas por diferentes percepções do que é a segurança.

Rara Rodrigues (2013), é necessário compreender a diferença entre riscos e ameaças para discorrer sobre o conceito de segurança, evidenciando que ambos os conceitos, estão associados à vulnerabilidade, entendida como pontos fracos que prejudicam a aptidão de um indivíduo em enfrentar os riscos (RODRIGUES, 2013).

Em relação a acessibilidade no que diz respeito a aspectos da topografia do terreno, onde está construído o condomínio, as entrevistas identificaram entraves à livre locomoção dos moradores, podendo gerar risco de acidentes, causando sensação de insegurança física para quem reside no local. Estudos afirmam que terrenos irregulares propiciam risco à saúde dos moradores, tornando-os mais propensos às quedas (NOVAES, et al. 2009). As irregularidades que o terreno apresentava afetavam negativamente a percepção dos moradores, dificultando a construção do lugar de moradia favorável, pois interferia no seu principal princípio, a "apropriação do espaço" - tornar um espaço próprio para uso.

Alguns entrevistados (88\%) justificaram motivos pelos quais reconhecem a importância de acessibilidade nos relatos: "o ambiente é propício para realização de 
atividades físicas, como caminhadas"; "há oferta de liberdade"; "favorece o uso de muletas e cadeira de rodas", reconhecendo ser imprescindível para atender às necessidades dos moradores; "inibe a ocorrência de quedas no local", e, por fim, tem-se no relato de um idoso que tal afirmação é justificada por haver "locais piores".

Vale destacar ainda, que um dos moradores (4\%) não soube responder se é importante ou não ter acessibilidade no conjunto habitacional. Considerando essas informações, é pertinente considerar qual o entendimento dos moradores sobre acessibilidade? Como essa importância pode ser reconhecida? Algumas variáveis podem inferir nesta percepção, como por exemplo, a ocorrência ou não de quedas, níveis de escolaridade, dentre outros aspectos relacionados à heterogeneidade dos moradores.

Reforçando essa hipótese, um dos entrevistados alegou que "a acessibilidade é importante porque existem locais piores". Nesse sentido, verifica-se como a percepção do que é um espaço acessível bem como a sua importância, está atrelada a possíveis experiências (a exemplo, residir anteriormente em local que as condições de acessibilidade eram precárias, possui alguma limitação física que prejudica sua locomoção, necessitando de locais adequados para caminhar, ou ainda, chegou a cair em locais que não eram acessíveis). Essa colocação remete a ambiência no sentido de que há condições objetivas e subjetivas que perpassam o físico, a dimensão arquitetural, e alcançam a percepção emocional e as experiências vivenciadas (THIBAUD, 2007).

Aos fundos do condomínio existe uma via férrea, sendo constante o tráfego de trens de carga. Para Brito, et al. (2013) a proximidade da passagem de trem ocasiona prejuízo à saúde física e psicológica das pessoas e danos nas edificações expostas ao padrão vibratório produzido. O autor justifica que a vibração alterna a cada passagem da composição da máquina, oscilando a intensidade, e pode ser agravado progressivamente pelo tempo de exposição (Brito et al., 2013). Para os imóveis expostos à vibração resulta em fadiga estrutural, fato este, observado nas paredes das casas do condomínio estudado com diversas rachaduras.

Diante deste cenário, $12 \%$ dos moradores afirma que o barulho do trem incomoda, mas alguns asseguram que o som remete às sensações de agradabilidade, como as visitas na infância na casa da avó ou, com a buzina do trem poder identificar o amigo maquinista. Essa subjetividade que perpassa o físico está presente na fala de uma idosa ao responde que "para alguns o trem é um problema, para mim não é, porque eu conheço o maquinista 
que é filho de um velho amigo, quando ele passa aqui ele buzina para mim e eu fico muito contente, os outros se incomodam. Além disso me faz lembrar de antigamente".

Assim, fica evidente que, sobre um mesmo aspecto, a percepção de um morador pode ser diferente dos demais, tendo em vista experiências, sensações e pontos de vista. Desta forma, as dimensões da ambiência são assim refletidas em situações cotidianas e aparecerem de forma espontânea em relatos pessoais.

Existem ainda outras expressivas referências a pontos positivos como, "a equipe que trabalha no local" e "as atividades proporcionadas no local". Esses se referem a vínculos estabelecidos entre os condôminos e a equipe responsável pela gestão, retratando relações de amizade, afinidades e afetos, e embora sejam relações restritas ao interior do condomínio, reforçam a questão da subjetividade envolvida nas condições de moradia e da ambiência, contribuindo para a qualidade de vida da pessoa idosa.

\section{Conclusões}

A Organização das Nações Unidas considera que a habitabilidade deve ser garantida a todas as pessoas valorizando sua subjetividade. Assim, para alcançar a habitabilidade à moradia necessita ser acrescida de condições que propiciem usufruir o ambiente e o entorno, fatores que promovem a integração socioespacial do morador.

Levando-se em conta que o ser humano reúne características biopsicossociais, não basta o abrigo fornecido pela construção de alvenaria, é preciso pensar um ninho, um aconchego. Atentar-se para um conjunto de condições e preferências que abarquem as especificidades de pessoas, em determinada localidade e em dado momento histórico representam tendências importantes para o alcance de sentido de pertencimento ao lugar de moradia. Essa sensação de pertencimento é definida por Thibaud (2010) como sendo onde "a ambiência se apoia, se constitui e repousa".

Entre a moradia e o local da habitação é necessário haver uma troca continua no sentido de transformar o "local" em um "lugar" na totalidade da sua essência. O estudo da ambiência merece, portanto, permear o direito à moradia, pois observando-se um conjunto de características sociais, culturais, emocionais que influenciam determinada população é possível aproximar-se do espaço ideal, que contemple a habitabilidade na vida cotidiana dos moradores. 
Nesse estudo analisou-se um condomínio exclusivo para pessoas idosas de baixa renda, uma política pública que aparece timidamente em algumas cidades brasileiras. Nas entrevistas, pode-se concluir que todos os moradores aprovaram essa tipologia, mas essa não é uma solução generalizada para o grande número de pessoas que envelhecem em condições econômicas muito vulneráveis. Para atender preferências ímpares se faz necessário diversificar as modalidades de políticas habitacionais que contemplem medidas tendentes a integrar a pessoa, articulando condições que instiguem o morador idoso a vivenciar o espaço da maneira mais independente e ativa possível.

Essas condições devem representar a somatória dos desejos pessoais mais a arquitetura proporcionada pelo lugar. Atender a esse conjunto de condições subjetivas e objetivas não é tarefa fácil na implementação de políticas habitacionais. No estudo apresentado, verificou-se que questões fundamentais, como a segurança e a acessibilidade são percebidas pelos moradores de forma diferente, dependendo do entendimento que eles detêm sobre o assunto e sobre a sua percepção dentro do condomínio. Nesse sentido, verificou-se grande diversidade dos moradores no perfil sociodemográfico, caracterizando pessoas vivendo na mesma comunidade com muita heterogeneidade.

Diante de tal heterogeneidade, ainda que haja grande empenho do poder público em implementar modalidades habitacionais adequadas às necessidades da população idosa, não se obterá uma percepção comum sobre o mesmo lugar de moradia. A exemplo disso, a questão do barulho do trem que transita aos fundos do condomínio, para a maioria dos entrevistados incomoda, mas, para um morador, o trem representa a aproximação do amigo maquinista que buzina, cumprimentando-o. Assim é a ambiência. Presente na diversidade de preferências, afetos e sensações, caracterizada espontaneamente e integrando o cotidiano das pessoas.

Nesse sentido, estudos interdisciplinares são preponderantes para a análise da ambiência como componente da moradia adequada para idosos de baixa renda. Aprofundar o conhecimento científico sobre o tema contribui para o bem-estar na velhice e para o envelhecimento ativo e saudável conforme preconizado pela Organização Mundial de Saúde. 


\section{Referências}

ASSOCIAÇÃO BRASILEIRA DE NORMAS TÉCNICAS - ABNT. NBR 9050/04: Acessibilidade a edificações, mobiliário, espaços e equipamentos urbanos. Rio de Janeiro: RJ, 2004. Disponível em: http://www.mpdft.gov.br/sicorde/NBR9050-31052004.pdf. Acesso em: 3 abr. 2015.

BRASIL. Lei n. 10.741, de 1 o de outubro de 2003. Dispõe sobre o Estatuto do Idoso e dá outras providências. Diário Oficial [da] República Federativa do Brasil,o, Brasília,3 out. 2003. Seção 1, p. 1.

Lei 13146/2015. Institui o Estatuto da Pessoa om Deficiência. http://www.planalto.gov.br/ccivil_03/_ato2015-2018/2015/lei/l13146.htm (Acessado em 03/jan/2017).

Ministério da Saúde. Secretaria de Atenção à Saúde. Núcleo Técnico da Política Nacional de Humanização. Ambiência. 2. ed. Brasília : Ed. Ministério da Saúde, 2010.

Secretaria de Direitos Humanos da Presidência da República. Direito à moradia adequada. Brasília: Coordenação Geral de Educação em SDH/PR, 2013. (Por uma cultura de direitos humanos).

BRITO, F. Transição demográfica e desigualdades sociais no Brasil. Revista Brasileira de Estudos de População, Rio de Janeiro, v. 25, n. 1, p. 5-26, jan. /jun. 2008. Disponível em:<http://www.scielo.br/pdf/rbepop/v25n1/v25n1a02.pdf> acesso: 30, out, 2013.

BRITO, L.A.; SOARES, A.M.S.; NAZARI, B. Vibração: Fonte de incômodo à população e de danos às edificações no meio urbano. Ambiente Construído, Porto Alegre, v. 13, n. 1, p. 129141, jan./mar. 2013.

CAMARANO, A. A; KANSO, S. Envelhecimento da população brasileira: uma contribuição demográfica. In: FREITAS, E.V. et al. Tratado de geriatria e gerontologia. 3. ed. Rio de Janeiro: Guanabara Koogan, 2011. p. 58-73.

CAMARANO, A. A.; PASINATO, M. T. O envelhecimento populacional na agenda das políticas públicas. In: CAMARANO, A. A. (Org.). Os novos idosos brasileiros: muito além dos 60? Rio de Janeiro: IPEA, 2004.

CAMARGO, M. C. S. et al. A relação entre renda e morar sozinho para idosos paulistanos, 2000: opção consciente ou carência de políticas públicas? Revista Brasileira de Estudos de População, Rio de Janeiro, 2007. Disponível em: http://www.repositorio.fjp.mg.gov.br/handle/123456789/66. Acesso em janeiro de 2016.

CHVATAL, K. M. S. Avaliação do procedimento simplificado da NBR 15575 para determinação do nível de desempenho térmico de habitações. Ambiente Construído, Porto Alegre, v. 14, n. 4,p. 119-134, out./dez. 2014.

COHEN, SC. Habitação saudável como um caminho para a promoção da saúde 2004. Tese (Doutorado) -Escola Nacional de Saúde Pública, Fundação Oswaldo Cruz, Rio de Janeiro, 2004. 
ELALI, G. A. Relações entre comportamento humano e ambiência: uma reflexão com base na psicologia ambiental. In: COLÓQUIO INTERNACIONAL AMBIÊNCIAS COMPARTILHADAS: CULTURA, CORPO E LINGUAGEM. AMBIENCES EM PARTAGE: CULTURE, CORPSETLANGUAGE, 2009, Rio de Janeiro, RJ. Anais ... Rio de Janeiro: ProArq - UFRJ, 2009. v. 1. p. 1-17.

GABRILLI, M. Desenho universal: um conceito para todos. 2013. Disponível em: . Acesso em: 15 mar. 2014.

INSTITUTO BRASILEIRO DE GEOGRAFIA E ESTATÍ́STICA - IBGE. Projeção da População do Brasil por Sexo e Idade para o Período 2000-2060 - Revisão 2013: Síntese de indicadores sociais: análise das condições de vida da população brasileira 2015.p.14. Disponível em: http://biblioteca.ibge.gov.br/visualizacao /livros/liv66777.pdf. Acesso em: 12 fev. 2016.

. Síntese de indicadores sociais : uma análise das condições de vida da população brasileira : 2015, Rio de Janeiro, 137p. Disponível em: http://ndonline. com.br/uploads/ global/materias/2015/12/04-12-2015-02-58-43-pesquisa-ibge.pdf. Acesso em: 12 fev. 2016

MALARD, M. L. Forma, Arquitetura. Interpretar Arquitetura, Belo Horizonte, v. 5, n. 6, p. 115, 2004.

MARTINS, M. S., ROMANINI, A, MUSSI, A. Q., FOLLE, D. Projeto de habitações flexíveis de interesse social. Campinas. 10-2. 301-31. Jul./dez. 2013. Disponívelem:[http://periodicos.puccampinas.edu.br/seer/index.php/oculum/article/viewFile/2148/1794. Acesso em: 12 fev. 2014.

MAFFESOLI, M. Comunidade de destino. Horizonte Antropológico, v. 12, n. 25, p. 273-283, 2006.

MELLO, J.B. F. A humanística perspectiva do espaço e do lugar. Acta Geográfica, Boa vista, v. 5, n. 9, 2011. Disponível em: http://revista.ufrr.br/index.php/actageo/article/view/429. Acesso em: 17 abr. 2015.

MICHAELIS. "Ambiência" In DICIONÁRIO de língua portuguesa. Disponível em: [ http://michaelis.uol.com.br/moderno-portugues/busca/portugues-

brasileiro/ambi\%C3\%AAncia/. Acesso em: 10 out. 2017.

NOGUEIRA, S, L.; ; RIBEIRO, R C. L. ; ROSADO L. E. F. P. L.; FRANCESCHINI S. C. C.; RIBEIRO, A. Q.; PEREIRA, E. T. Fatores determinantes da capacidade funcional em idosos longevos. Revista Brasileira de Fisoterapia, São Carlos, v. 14, n. 4, p. 322 -329, Ago. 2010. Disponível em: http://www.scielo.br/scielo.php?script=sci_arttext\&pid=S1413-35552010000400009 \&lng=en\&nrm=isso. Acesso em: 11 maio 2015

NOVAES, R.D.; SANTOS, E.C.; MIRANDA, A.S.; LOPES, K.T.; RIUL, T.R. Causas e consequências de quedas em idosos como indicadores para implementação de programas de exercício físico. Efdesportes: Revista digital. Buenos Aires, Abr. 2009. Disponível em: http://www.efdeportes.com/efd131/causas-e-consequencias-de-quedas-em-idosos.htm. Acesso em: 21 abr. 2015. 
OHCHR; UN-Habitat. The righttoadequatehousing. Geneva: Office ofthe United Nations High Commissioner for HumanRights. New York: UN-Habitat, 2009.

ORGANIZAÇÃO MUNDIAL DE SAÚDE . CID-10 - Centro colaborador da OMS para a classificação de doenças em português. 4. ed. São Paulo: Edusp, 1997.

PERRACINI, M. R. Planejamento e Adaptação do Ambiente para Pessoas Idosas. In: FREITAS, E.V. et al. Tratado de geriatria e gerontologia. Rio de Janeiro: Guanabara Koogan, 2011. p.1311,1323.

PRADO, A. R. A.; PERRACINI, M. R. A construção de ambientes favoráveis aos idosos. In: NERI, A. Qualidade de vida na velhice. Campinas: Alínea, 2011.

PRIBERAM. “Ambiência” In: DICIONÁRIO da Língua Portuguesa. 2008-2013, Disponível em: http://www.priberam.pt/dlpo/AMBIENCIA. Acesso em: 3 mar. 2016.

RHEINGANTZ, P A. Uma pequena digressão sobre conforto ambiental e qualidade de vida nos centros urbano. Cidade \& Ambiente, Santa Maria, v. 1, n. 22, p. 35-58, jan./jun. 2001.

RODRIGUES, A.R. O conceito de segurança. Jornal de Defesa e Relações Internacionais. Disponível em

http://database.jornaldefesa.pt/politicas_de_defesa/portugal/JDRI\%20047\%20090413\%20 conceito\%20seguran\%C3\%A7a.pdf. Acesso em: 12 fev. 2016.

SANT'ANNA, A. S.; KILIMNIK, Z. M. (Org.). Qualidade de vida no trabalho: abordagens e fundamentos. Rio de Janeiro: Elsevier, 2011.

SANTOS, S. M. et al . Associação entre fatores contextuais e auto-avaliação de saúde: uma revisão sistemática de estudos multinível. Caderno de Saúde Pública, Rio de Janeiro, v. 23, n. 11 , p. 2533-2554, nov. 2007

THIBAUD, J-P. “A cidades através dos sentidos" ,"La ville à l'épreuvedessens" In: COUTARD, O.; LÉVY, J.P. Ecologies Urbaines. Paris, 2010. p. 198-213. Disponível em: http://www.proarq.fau.ufrj.br/revista/public/docs/Proarq18_ACidade_JeanThibaud.pdf. Acesso em: 23 mar. 2015.

. A cidades através dos sentidos. Cadernos PROARQ, p. 1-16, 2012. Disponível em: http://www.proarq.fau.ufrj.br/revista/public/docs/Proarq18_ACidade_JeanThibaud.pdf. Acesso em: 22 mar. 2015.

TUAN, Y-F. Espaço e lugar: a perspectiva da experiência. São Paulo: Difel, 1983.

. Geografia humanística. In: CHRISTOFOLETTI, A. (Org.). Perspectivas da geografia. São Paulo: DIFEL, 1982. p. 143-164.

. Espaço e lugar: a perspectiva da experiência. Londrina: Eduel, 2013.

VERAS, R. Envelhecimento populacional contemporâneo: demandas desafios e inovações, Revista de Saúde Pública, São Paulo, v. 43, n. 3, p. 548-554, 2009. 